\title{
Klasifikasi Rempah Rimpang Berdasarkan Ciri Warna RGB Dan Tekstur GLCM Menggunakan Algoritma Naive Bayes
}

\author{
Nadya P. Batubara ${ }^{1}$, Didit Widiyanto ${ }^{2}$, Nurul Chamidah ${ }^{3}$, \\ Program Studi Informatika, Fakultas Ilmu Komputer \\ Universitas Pembangunan Nasional Veteran Jakarta \\ Jl. Rs. Pondok Labu Jakarta Selatan 12450 \\ nadyapermatasari48bb@gmail.com
}

\begin{abstract}
Abstrak. Pada penelitian ini akan membahas bagaimana cara mengklasifikasikan beberapa jenis rempah berdasarkan algoritma Naïve Bayes. Menggunakan ekstraksi ciri warna RGB dan tekstur GLCM. Tahapan dalam proses klasifikasi citra digital pada penelitian ini yaitu praproses citra, segmentasi, ekstraksi ciri, klasifikasi dan uji performa. Proses yang dilakukan pada penelitian ini adalah mengubah RGB to Grayscale untuk mendapatkan citra abunya, setelah mengubah citra menjadi Grayscale. Citra di segmentasi dengan thresholding menggunakan metode Otsu. Setelah mendapatkan hasil dari segmentasi dilakukan RoI (Region of Interest) yang menghasilkan perkalian pixel. Selanjutnya dilakukan ekstraksi ciri dengan menggunakan GLCM (Grey Level Co-occurrence Matrix) dan ekstraksi fitur RGB (Red, green, blue) yang di ekstrak ke dalam GLCM. Setelah mendapatkan hasil dari ekstraksi ciri maka dilakukan klasifikasi menggunakan algoritma Naïve Bayes. Tahapan terakhir pada penelitian ini adalah uji performa menggunakan $K$-fold cross validation dengan $\mathrm{K}=10$ dan mendapatkan hasil akurasi sebesar 52\%.
\end{abstract}

Kata Kunci: Rempah-rempah, Naïve Bayes, RGB, GLCM.

\section{Pendahuluan}

Pada zaman modern ini, banyak orang yang berminat untuk mencari obat yang alami serta mencoba cara dengan mengkonsumsi obat-obatan dari alam tanpa adanya campuran dari bahan kimia. Alasannya adalah karena harganya yang murah dan terjangkau, memiliki khasiat yang ampuh dari obat-obat buatan pabrik, memiliki kesan yang lebih alami, mudah di dapatkan di pasar tradisional maupun di alam, tidak terlalu memiliki efek samping yang berlebihan, berbeda dengan obat kimia yang khusus untuk mengobati satu jenis penyakit tertentu, tanaman obat memiliki khasiat yang beragam. Ketepatan pemilihan bahan baku obat herbal tidak hanya pada jenis tanaman, tetapi juga bagian tanaman yang digunakan. Disebabkan setiap bagian tanaman memiliki khasiat khusus yang berbeda. Inilah alasan semua orang mulai gencar mengkonsumsi rempah-rempah sebagai obat-obatan. Serta dalam membeli maupun mengkonsumsi rempah-rempah jangan sampai salah memilih, supaya cocok dan dapat mengobati gejala penyakit yang sedang anda alami. Untuk orang awam seperti orang yang hidup di kota pasti ketika mengetahui rempah sejenis kunyit, lengkuas, jahe, dan temulawak sekilas sama. Dan kebanyakan untuk orang awam sering menyebut bahwa itu adalah kunyit atau jahe namun yang sebenarnya itu adalah lengkuas. Dengan teknologi yang berkembang saat ini maka sangat memungkinkan jika melakukan klasifikasi citra digital untuk membedakan kunyit, lengkuas, jahe, temulawak.

\section{Tinjauan Pustaka}

\subsection{Rempah}

Jenis rempah sangat banyak dan ide penelitian ini mengambil 4 jenis rempah yang sulit dibedakan yaitu kunyit, temulawak, jahe dan lengkuas [1]. Kunyit adalah jenis rempah khas Indonesia. Kunyit banyak digunakan oleh masyarakat sebagai bahan makanan ataupun digunakan sebagai jamu. Kunyit berwarna kuning sehingga banyak digunakan sebagai bahan pewarna makanan. Kunyit sangat bermanfaat untuk menurunkan tekanan darah, obat 
cacing, obat asma, penambah darah, mengobati sakit perut, penyakit hati, stimulan, gatal-gatal, gigitan serangga, diare, rematik.

Temulawak adalah tanaman yang tumbuh merumpun. Temulawak merupakan bagian dari jenis rempah yang bermanfaat untuk pengobatan dan memiliki prospek yang baik jika dikembangkan. Lengkuas (Alpinia galanga) adalah salah satu tanaman yang berguna untuk obat-obatan, kosmetik dan kesehatan yang digunakan pada bagian buah, batang, daun, maupun akar. Berdasarkan ilmu pengetahuan yang berhubungan dengan obat-obatan (farmakologis), ekstrak lengkuas dapat dimanfaatkan sebagai anti jamur, anti kanker, anti tumor, antioksidan, sitotoksik.

Jahe adalah jenis rempah yang sering digunakan pada bahan makanan maupun minuman. Untuk dunia kesehatan jahe dapat digunakan sebagai obat masuk angin, gangguan pencernaan, sebagai analgesik, antipiretik, antiinflamasi.

\subsection{Grayscale}

Untuk melakukan perubahan suatu gambar full color (RGB) menjadi suatu citra grayscale (gambar keabuan), metode yang umum digunakan, dimana R: Unsur warna merah G : Unsur warna hijau B : Unsur warna biru. Nilai yang dihasilkan dari persamaan diatas akan diinput ke masing-masing unsur warna dasar citra grayscale [2].

\subsection{RGB (red, green, blue)}

RGB terdiri dari 3 warna komponen yaitu Red, Green, dan Blue. Red memiliki nilai piksel 0-255, green memiliki nilai piksel 0-255, dan blue memiliki nilai piksel 0-255. RGB menjadi grayscale dengan rumus sebagai berikut pada formula 1[3]:

$$
\text { Grayscale }=0,299 \mathrm{R}+0,587 \mathrm{G}+0,114 \mathrm{~B}
$$

\subsection{HSV (Hue, Saturation, Value)}

Saturation yaitu ukuran banyaknya cahaya putih yang bercampur pada hue [4].

\subsection{Metode Otsu}

Metode otsu melakukan analisis diskriminan dengan menentukan suatu variable dengan membedakan antara dua atau lebih secara alami. Metode otsu dimulai dengan normalisasi histogram citra sebagai fungsi probability discrete density [5].

\subsection{GLCM}

GLCM merupakan salah satu dari beberapa metode dalam mengekstraksi fitur. Dalam suatu matriks citra dilakukan perhitungan analisis tekstur berdasarkan percampuran intensitas piksel pada posisi tertentu, meliputi:

1) Kontras

Perhitungan kontras berkaitan dengan jumlah keberagaman intensitas keabuan dalam citra.

2) Homogenitas

Homogenitas GLCM adalah invers dari kontras GLCM, yaitu keseragaman intensitas keabuan pada citra.

3) Energi

Energi menyatakan ukuran konsentrasi pasangan dengan intensitas keabuan tertentu pada matriks.

4) Entropi

Entropi digunakan untuk mengukur keteracakan dari distribusi intensitas.

\subsection{Normalisasi}

Normalisasi adalah suatu pendekatan sistematis untuk meminimalkan redundancy (kejadian berulangannya suatu data atau kumpulan data yang sama dalam sebuah database yang dapat mengakibatkan pemborosan media 
penyimpanan) agar database tersebut dapat bekerja secara maksimal. Rumus normalisasi dapat diterapkan dengan rumus pada formula 1:

$$
\operatorname{Norm}_{(x)}=\frac{X-\text { MinValue }}{\text { MaxValue-MinValue }}
$$

\subsection{Naïve Bayes}

Naive Bayes merupakan pengklasifikasian dengan metode probabilitas dan statistika yang dikemukakan oleh ilmuwan Inggris Thomas Bayes.Pada metode ini, semua atribut akan memberikan kontribusinya dalam pengambilan keputusan, dengan bobot atribut yang sama penting dan setiap atribut saling bebas satu sama lain. Algoritma Naive Bayes adalah probabilitas sederhana classifier yang menghitung satu set probabilitas oleh menghitung frekuensi dan kombinasi nilai dalam satu set data yang diberikan. Algoritma menggunakan teorema Bayes dan menganggap semua atribut bersifat independen mengingat nilai variabel kelas. Ini bersyarat Asumsi independensi jarang benar dalam kenyataan aplikasi dunia, maka karakterisasi sebagai Naif namun algoritma cenderung berkinerja baik dan belajar dengan cepat di berbagai klasifikasi yang diawasi masalah dapat dilihat pada formula 2:

$$
P(H \mid X)=\frac{P(X \mid H)}{P(X)} \cdot P(H)
$$

\section{Metode Penelitian}

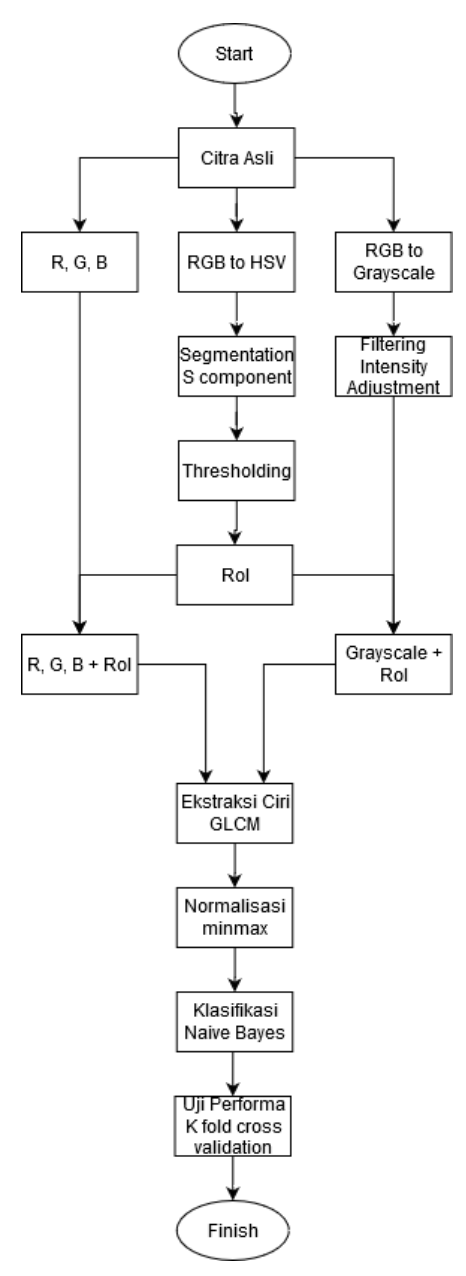

Gambar 1. Diagram Alir Sistem

ISSN : 2655-139X (ONLINE) 


\subsection{Citra Asli}

Citra asli yang digunakan yaitu citra rempah yang terdiri dari kunyit 20 gambar, temulawak 20 gambar, lengkuas 20 gambar, dan jahe 20 gambar.Citra rempah tersebut diambil dari kamera smartphone dan menggunakan background kertas HVS.

\subsection{Pra proses Citra}

Pada tahap pra proses ini bertujuan untuk memperbaiki kualitas citra (image enhancement) pada citra kunyit, jahe, temulawak dan lengkuas.Dengan tahapan sebagai berikut :

\subsubsection{RGB (red, green, blue)}

Mengambil masing-masing channel RGB yaitu channel Red, Green dan Blue pada citra asli.

\subsubsection{RGB to Grayscale}

Tahapan dalam konversi RGB to Grayscale adalah membaca citra/image kunyit, jahe, temulawak, dan lengkuas. Melakukan konversi citra kunyit, jahe, temulawak, dan lengkuas

\subsubsection{Intensity Adjustment}

Menaikkan contrast gambar dengan memetakan nilai-nilai intensitas gambar input ke nilai-nilai baru sehingga citra yang semula memiliki intensitas rendah memiliki intensitas tinggi.

\subsubsection{RGB to HSV (hue, saturation, value)}

Tahapan dalam mengkonversi RGB to HSV yaitu dengan mengekstrak masing-masing komponen HSV yaitu Hue, Saturation, dan Value. Setelah mencoba masing-masing komponen pada citra rempah. Komponen S (saturation) adalah komponen yang paling tepat untuk melakukan proses selanjutnya yaitu proses segmentasi.

\subsection{Segmentasi Citra}

Tujuan dari segmentasi citra adalah untuk memisahkan wilayah objek dengan wilayah background. Segmentasi dilakukan dengan mengambil komponen S (saturation) dari proses RGB to HSV. Dengan tahapan sebagai berikut:

\subsubsection{Otsu/Thresholding}

Pada tahap ini dilakukan thresholding dengan metode otsu untuk mendapatkan nilai ambang pada citra kunyit, jahe, temulawak, dan lengkuas. Nilai Ambang yang akan dicari dari suatu citra gray level dinyatakan dengan $\mathrm{k}$. Nilai $\mathrm{k}$ berkisar antara 1 sampai dengan $\mathrm{L}$, dengan nilai $\mathrm{L}=255$.

\subsubsection{RoI (Region of Interest)}

Pada tahap segmentasi selanjutnya mengambil wilayah yang diinginkan yaitu wilayah objek pada citra jenis rempah dengan metode Region of interest (RoI) pada penelitian ini objeknya yaitu citra kunyit, lengkuas, temulawak dan jahe. Keluaran dari proses ini berupa citra thresholding x image enhancement dari kunyit, lengkuas, temulawak dan jahe.

\subsubsection{RoI + Grayscale}

Image citra grayscale yang sudah di filtering lalu di masking dengan citra kunyit, temulawak, lengkuas, dan jahe yang sudah di RoI.

\subsubsection{RoI + RGB}

Masing-masing channel citra R (red), G ( green), dan B (blue) di masking dengan citra kunyit, temulawak, lengkuas, dan jahe yang sudah di RoI. 
Setelah dilakukan pra proses dan segmentasi.citra hasil ekstraksi RoI (region of interest) akan digunakan dalam tahap ekstraksi fitur GLCM (gray level co occurrence matrix) dan RGB (red, green, blue) yaitu dengan memasukkan masing-masing dari channel Red, Green, dan Blue ke dalam GLCM pada proses selanjutnya.

\subsection{Ekstraksi Ciri}

Tahap ekstraksi fitur dilakukan untuk mengambil ciri tekstur GLCM (Gray co occurrence matrix) dan RGB (red, green, blue) yang telah di ekstrak ke dalam GLCM dari citra kunyit, jahe, temulawak, dan lengkuas. Pada ekstraksi ini mengambil nilai homogeneity, contrast, correlation, dan energy dengan derajat $0^{\circ}, 45^{\circ}, 90^{\circ}$ dan $135^{\circ}$.

\subsection{Normalisasi}

Normalisasi adalah suatu teknik yang dilakukan untuk tidak adanya selisih angka dengan angka yang lainnya dan juga menghilangkan kerangkapan data pada hasil ekstraksi ciri GLCM.

\subsection{Klasifikasi}

Pada tahap klasifikasi bertujuan untuk menentukan kelas, apakah jenis rempah tersebut merupakan citra kelas kunyit, jahe, temulawak, dan lengkuas. Metode yang digunakan pada klasifikasi jenis rempah adalah dengan algoritma Naïve Bayes.

\subsection{Naïve Bayes}

Langkah untuk pelatihan data citra kunyit, lengkuas, temulawak, dan jahe pada metode Naïve Bayes adalah melakukan klasifikasi naïve bayes dengan menghitung nilai probabilitas dari ekstraksi ciri GLCM dan RGB yang telah di ekstrak ke dalam GLCM. Nilai dari ekstraksi fitur GLCM dan RGB yang telah di ekstrak ke dalam GLCM. Tiap kelas citra rempah diklasifikasikan sesuai dengan nilai probabilitas yang didapatkan.

\subsection{Uji Performa}

Metode ini digunakan untuk mengevaluasi kinerja model algoritma yang digunakan. Algoritma yang digunakan pada penelitian ini yaitu algoritma Naïve Bayes. Dengan dataset citra kunyit, temulawak, lengkuas dan jahe yang sudah melalui ekstraksi ciri GLCM dan RGB. Uji performa akan dilakukan dengan menggunakan $K$-fold cross validation.

\section{Hasil dan Pembahasan}

\subsection{Pra proses Citra}

Citra asli pada pra proses ini adalah citra rempah.Citra rempah terdiri dari: Kunyit 20 gambar, Jahe 20 gambar, Lengkuas 20 gambar dan Temulawak 20 gambar. Dengan total keseluruhan citra adalah 80 gambar. Pra proses yang dilakukan yaitu dengan mengambil nilai RGB atau $R$ (red), $G$ (green), dan B (blue) pada citra rempah.Setiap piksel dalam citra RGB memiliki nilai intensitas dari nilai Red, Green, dan Blue.

Pada tahap pra proses ini bertujuan untuk memperbaiki kualitas citra (image enhancement) pada citra kunyit, jahe, temulawak dan lengkuas.Dengan tahapan sebagai berikut :

a) RGB (red, green, blue)

Mengambil masing-masing channel RGB yaitu channel Red, Green dan Blue pada citra asli.

\section{b) RGB to Grayscale}

Tahapan dalam konversi RGB to Grayscale adalah membaca citra/image kunyit, jahe, temulawak, dan lengkuas. Melakukan konversi citra kunyit, jahe, temulawak, dan lengkuas 


\section{c) Intensity Adjustment}

Menaikkan contrast gambar dengan memetakan nilai-nilai intensitas gambar input ke nilai-nilai baru sehingga citra yang semula memiliki intensitas rendah memiliki intensitas tinggi.

\section{d) RGB to HSV (hue, saturation, value)}

Tahapan dalam mengkonversi RGB to HSV yaitu dengan mengekstrak masing-masing komponen HSV yaitu Hue, Saturation, dan Value. Setelah mencoba masing-masing komponen pada citra rempah. Komponen S (saturation) adalah komponen yang paling tepat untuk melakukan proses selanjutnya yaitu proses segmentasi.

\subsection{Segmentasi Citra}

Pada tahap segmentasi citra ini dilakukan konversi ruang warna yang semula RGB menjadi HSV (Hue, Saturation, Value) lalu mengekstrak komponen S (Saturation) pada citra HSV. Mengambil komponen S dikarenakan pada komponen H (Hue) dan V (Value) hasil segmentasi tidak membentuk objek yang diinginkan.Pada Tabel 1 menunjukkan hasil dari citra pada komponen H (Hue), komponen S ( Saturation) dan komponen V (Value).

Tabel 1. Citra HSV (hue, saturation dan value)

\begin{tabular}{|c|c|c|}
\hline Citra $\mathrm{H}($ Hue $)$ & Citra S (Saturation) & Citra V (Value) \\
\hline & &
\end{tabular}

\subsection{Morfologi}

Metode $o t s u$ belum bisa sepenuhnya mensegmentasi rempah, dikarenakan masih terdapat banyak noise dalam citra objek rempah. Pada tahap ini dilakukan morfologi pada citra biner hasil segmentasi otsu. Operasi yang digunakan adalah opening yaitu erosi kemudian dilasi Erosi melakukan pengikisan area piksel pada objek kunyit, temulawak, lengkuas dan jahe. Dilasi melakukan penambahan area piksel pada objek kunyit, temulawak, lengkuas dan jahe.Perbandingan citra erosi kunyit, temulawak, lengkuas dan jahe dengan citra dilasi.

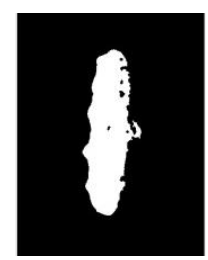

(a)

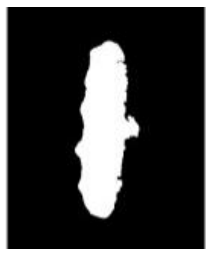

(b)

Gambar 2. (a) Citra Dilasi (b) Citra Erosi

\subsection{Region of Interest}

Pada tahap segmentasi selanjutnya mengambil wilayah yang diinginkan yaitu wilayah objek pada citra jenis rempah dengan metode Region of interest (RoI) pada penelitian ini objeknya yaitu citra kunyit, lengkuas, temulawak dan jahe.Keluaran dari proses ini berupa citra thresholding x image enhancement dari kunyit, lengkuas, temulawak dan jahe

\subsubsection{RoI + Grayscale}

Image citra grayscale yang sudah di filtering lalu di masking dengan citra kunyit, temulawak, lengkuas, dan jahe yang sudah di RoI. 


\subsection{2 $\operatorname{RoI}+R, G, B$}

Masing-masing channel citra R (red), G ( green), dan B (blue) di masking dengan citra kunyit, temulawak, lengkuas, dan jahe yang sudah di RoI.

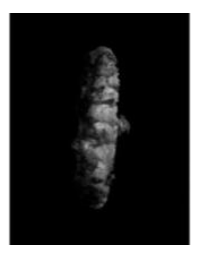

(a)

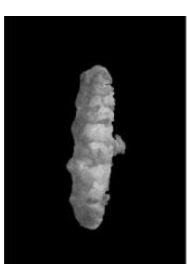

(b)

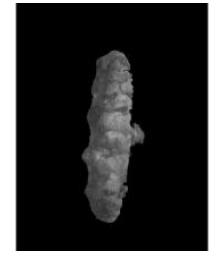

(c)

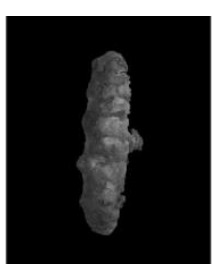

(d)

Gambar 3. (a) Mask + Grayscale, (b) Mask + Red, (c) Mask + Green,(d) Mask + Blue

Setelah dilakukan pra proses dan segmentasi.citra hasil ekstraksi RoI (region of interest) akan digunakan dalam tahap ekstraksi fitur GLCM (gray level co occurrence matrix) dan RGB (red, green, blue) yaitu dengan memasukkan masing-masing dari channel Red, Green, dan Blue ke dalam GLCM pada proses selanjutnya.

\subsection{Ekstraksi Ciri}

Pada tahap ekstraksi ciri ini mengambil dari citra yang sudah di masking, yang kemudian diolah menggunakan ekstraksi ciri GLCM (gray level co-occurrence matrix) pada citra grayscale dan GLCM pada citra channel Red, Green dan Blue.Dengan mengambil nilai homogeneity, correlation, contrast, energy. Derajat $0^{\circ}, 45^{0}, 90^{\circ}$, dan $135^{0}$.

Tabel 2. Hasil Ekstraksi Ciri

\begin{tabular}{|c|c|}
\hline Homogeneity 0 & 0,9949 \\
\hline Contrast 0 & 0,0119 \\
\hline Correlation 0 & 0,9000 \\
\hline Energy 0 & 0,9493 \\
\hline
\end{tabular}

\subsection{Normalisasi}

Hasil ekstraksi ciri GLCM dari citra grayscale, channel Red, channel green, dan channel blue. Selanjutnya akan di normalisasi untuk menyamakan rentang nilai dengan normalisasi min-max, dengan min sebesar 0,9485 dan max sebesar 1 pada ekstraksi ciri GLCM grayscale fitur homogeneity derajat 0 pada data 1 yang dapat dilihat perhitunganya pada rumus.

$$
\begin{gathered}
\text { Normalisasi }(x)=\frac{(X-\text { MinValue })}{(\text { MaxValue-MinValue })} \\
\text { Normalisasi }(x)=\frac{(\text { citra homogeneity } 0-0,9486)}{(1-0,9485)} \\
\text { Normalisasi }(x)=\frac{(0,9949,-0,9485)}{(1-0,9485)} \\
\text { Normalisasi }(x)=\frac{(0,0464)}{(0,0515)} \\
\text { Normalisasi }(x)=0,9009
\end{gathered}
$$

Tabel 3. Hasil Normalisasi Data

\begin{tabular}{|c|c|}
\hline Homogeneity 0 & 0.9009 \\
\hline Contrast 0 & 0,0948 \\
\hline Correlation 0 & 0,9223 \\
\hline Energy 0 & 0.9000 \\
\hline
\end{tabular}




\section{JURNAL INFORMATIK Edisi ke-16, Nomor 3, Desember}

\subsection{Klasifikasi}

Data yang telah didapat dari ekstraksi ciri GLCM citra grayscale dan ekstraksi ciri GLCM channel Red, channel Green, and channel Blue yang sudah di normalisasi kemudian dilakukan klasifikasi menggunakan algoritma naïve bayes gaussian. Statement matlab yang digunakan pada algoritma naïve bayes Gaussian adalah $n b=$ fitcNB(X(train,:),Y(train,:); dengan $\mathrm{X}=$ data kelas yaitu terdapat 4 kelas, kelas kunyit, temulawak, lengkuas, dan jahe.Y adalah atribut yang digunakan pada citra grayscale, citra red, citra green dan citra blue yaitu GLCM $0^{0}, 45^{\circ}, 90^{\circ}$, dan $135^{\circ}$ dengan mengambil homogeneity, correlation, contrast, energy. Klasifikasi menggunakan algoritma Nä̈ve Bayes. Confusion matrix dari metode Nä̈ve Bayes tersebut dijabarkan sebagai berikut:

$$
\begin{gathered}
\text { Accuracy }=\frac{\Sigma \text { seluruh akurasi }}{\Sigma \mathrm{K}=10} \\
\text { Accuracy }=\frac{62 \%+50 \%+50 \%+62 \%+50+50 \%+50 \%+50 \%+50 \%+50 \%}{10}=52,4 \%
\end{gathered}
$$

Akurasi yang didapat adalah 52\%. Maka performa dari metode Nä̈ve Bayes menggunakan K-fold cross validation mendapat nilai accuracy $52 \%$.

\section{Penutup}

\subsection{Kesimpulan}

Kesimpulan yang dapat diambil setelah melakukan tahapan dari penelitian terhadap citra kunyit, temulawak, lengkuas dan jahe dengan pra proses grayscale, dan channel $R, G, B$ serta melakukan segmentasi menggunakan citra HSV dengan mengambil komponen Saturation dan melakukan ekstraksi ciri yang berdasarkan ciri tekstur dan warna menggunakan GLCM pada citra grayscale dan GLCM pada citra channel Red, channel Green, dan channel Blue. Kemudian dilakukan normalisasi data terhadap hasil ekstraksi ciri. Hasil dari data normalisasi tersebut kemudian di klasifikasi dengan algoritma Nä̈ve bayes dengan $k$-fold cross validation $\mathrm{K}=10$ mendapatkan hasil accuracy dengan nilai 52\%. Hasil accuracy 52\% karena menggunakan 4 objek jadi membutuhkan ekstraksi ciri lebih lanjut.

\subsection{Saran}

Berdasarkan hasil penelitian yang sudah dilakukan, diperlukan uji coba dengan pengembangan ekstraksi ciri pada penelitian lebih lanjut. Tahapan mengekstrak ciri atau informasi dalam citra digital sangat mempengaruhi untuk mengenali objek yang ada dalam citra tersebut. Sehingga semakin banyak ciri yang diekstrak akan mempengaruhi tingkat akurasi klasifikasi citra. Agar dapat menghasilkan akurasi yang lebih akurat.

\section{Referensi}

[1] L. Hakim., Etnobotani dan Manajemen Kebun-Pekarangan Rumah: Etnobotani dan Manajemen Kebun-Pekarangan Rumah: Ketahanan Pangan, Kesehatan dan Agrowisata. 2014.

[2] M. R. Kumaseh, L. Latumakulita, and N. Nainggolan, "Segmentasi Citra Digital Ikan Menggunakan Metode Thresholding,” J. Ilm. Sains, vol. 13, no. 1, p. 74, 2013, doi: 10.35799/jis.13.1.2013.2057.

[3] A. Anggie, "P Rogram S Tudi D Oktor," Pemodelan Arsit. Sist. Inf. Perizinan Menggunakan Kerangka Kerja Togaf Adm, vol. 4, no. 1, p. (halaman 2), 2018.

[4] A. Ciputra, D. R. I. M. Setiadi, E. H. Rachmawanto, and A. Susanto, "Klasifikasi Tingkat Kematangan Buah Apel Manalagi Dengan Algoritma Naive Bayes Dan Ekstraksi Fitur Citra Digital," Simetris J. Tek. Mesin, Elektro dan Ilmu Komput., vol. 9, no. 1, pp. 465-472, 2018, doi: 10.24176/simet.v9i1.2000.

[5] S. I. Syafi'i, R. T. Wahyuningrum, and A. Muntasa, "Segmentasi Obyek Pada Citra Digital Menggunakan Metode Otsu Thresholding," J. Inform., vol. 13, no. 1, pp. 1-8, 2016, doi: 10.9744/informatika.13.1.1-8. 